LA-UR -86-860 (ONE-860324--1') Received ly OSTI

APR $0 \div 1986$

TITLE: MAGNETIC-FUSION DATA ACQUISITION AT LOS ALAMOS

SUBMITTED TO PROCEEDINGS ON SIXTH TOPICAL CONFEFENCE ON HIGH TEMPERATURE PLASMA DIAGNOSTICS, HILTON HEAD ISLAND, SOUTH CAROLINA, MARCH 8-13, 1986

LA-UR- $-86-867$

AUTHOR(S): R. W. WILKINS and K. A. KLARE

DE86 008720

\title{
DISCLAIVIE: R
}

This report was prepured as un uccount of work sponsered $h_{;}$un ugency of the United States Government. Neither the United States Governnient nor uny agency thereof, nor uny of their employees, makes uny warranly, express or implied, ur ansumes any legal liability or renpunsi. hility for the llccurncy, completeness, or usefolness of uny informution, apparatus, product, of presesn discloned, or represents that its use would not infringe privalely owned rights. Re'erenco herein lo any specific commescual prokluct, process, or service by Irade name. Iradeinark. nunufucturer, or otherwise does not necessurily constitute or imply its endoracinent, recommendution of favoring by the United Statis Govermment or nny agency the eof. The views and opinions of authors expresed hereill lo not necensurily slate or reflect those of the Uniled Staten riovernment or uny Hgency therest

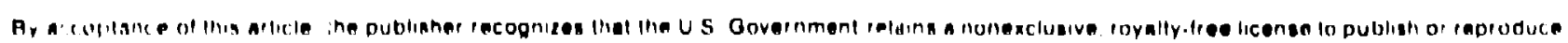

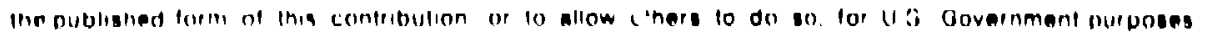


Magnetic-Fusion Data Acquisition at Los Alamos

R. W. Wilkins and K. A. Klare

Los Alamos National Laboratory, Los Alamus, New Mexico 87544

The CTR division uses a single software package to acquire data from hund-ajs of CAMAC recorders. For the past five years, this package has been used by all experiments, both manual and computer controlled. A variety of signals are stored in transient digitizers and other memorles. The computer retrieves the data and applies an efficient compression algorithm before storing it on disk. The physicist can plan his next shot from the acquired data even as the rest is read. The readout is list-directed with device, amplifier, and time base types and their settings selecied by the physicist. A new experiment may be set up in minutes. 
INTRODUCTION

Before the development of this acquisition software, each CTR experiment at Los Alamos had its nun acquisition system and file format. This state made software maintenance difficult. At least one programmer had to be familiar with each. system and analysis programs could not be transferred without change betweer experiments.

With these problems in mind, new data acquisitiun, analysis, and display programs were designed. In these programs, called DAD, ${ }^{1}$ all experiment and device-specific information is in descriptor files. This separation allows the same progiam to be used for all experiments.

I. HARDHARE

The computer systems used are:

1. A mint to control each machine.

2. A mini to acquire experimental data.

3. A large mini for immediate analysis.

4. A main frame for more extensive analysis and larger archiving caobility.

5. A satellite link to the DOE/MT: computer center at the Lawrence Livermote Natloral Laborato-y (LLNL). The large scale Chay and CDC 
computers theie are used by the experimentalists primarily for electrical network analysis and modeling.

Individual computers sometimes serve multiple functions among items 1 to 3 . The largest experiment is $2 T-40 M$, a reversed field toroldal z-pinch. It has a Prjme-750 that does control, acquisition, and on-line analysis. The Compact Torus Experiment (CrX) and the Field Reversed Experiment (FRX-C) share a Prime-400 for acquisition and analysis. Each has a Prime-300 for control of their machine. The toroidal z-pinch prototype (2T-P) d: served by a Prime-40C with some control by I.SI-11 microcomputers.

An X.25 link between the $2 \mathrm{~T}-40 \mathrm{M}$ computer and the VAX cluster glves rapid transfer of data from the experiment to a larger data base.

A PRIMENET link of ZT-P and 2T-40M permits sharing of resources including programs and computer hardware.

\section{DESCRIPTOR FILES}

The descriptors are of four types: logical device, time base, diagnostic, and shot. 
Each logical device descriptor has the model or type of the data acquisition device, its CAMAC address, the physical units measured, and a scale factor betwen the recorded signal voltage and the measured value. The amplifier and time base are also described. The total entry may have additional floating point numbers that are defined by the user. Typical uses are for probe positions or wavelergth settings in a diagnostic or for a calibration reference. Most data collection is with analog-to-digital transient recorders with memories up to $32 k$ samples.

A time base descriptoi may "gang" many devices to one set of numbers. This may be an external clock. The sample rate and number of samples are given for each rate. The devices used are listed for cross-reference.

A diagnostic descriptor lists all logical devices associated with a given diagnostic and the staius of the diagnostic. Th1s status maiks If the group of Luglcal devices is to be lgnored, read hut not kept beyond the next shol, or read and archived.

The shot descriptor has data that applies in common to all devices ruch as the shot number, tlme of day, voltage settings, fill pressures, and time delay settings. 
These tables are kept up-to-date using a utility program called DUTIL. This interactive program can be used by anyone associated with that experiment. With this program, the user can define new devices and diagnostics or change the tables of existing ones. In our experience, this open system approach has worked well, and is an Important factor in the acceptance of the system by its users.

To set up a total data set for a diffeient experiment, we must create a disk directory with the name of the experiment, create an empty set of descriptor flles in the directory, create an area for archived shots, and begin fllling in the descriptors using DUTIL. An "experiment" may be as large as $2 \mathrm{~T}-40 \mathrm{M}$ or a single recording device on a serial highway in a remote laboratcry.

IIT. DATA ACOUISITION COMMANDS

The date ecquistition commands of DAD are ARM, BASE, CLOSE, OPEN, READ, SAVE, and TRIG. The OPEN and CLOSE commands lock and release the descriptor files. The BASE rommand reads rocordes when the signal is thactive (base line) and, if posstble, reuds them with no inpul (npen clrcult) to measure absolute voltages. The ARM, 
BASE, READ, and TRIG (trigger) commands may be changed by arguments that restitct them to one diagnostic set or a single logical device. The programs now support many different hardware models and operational modes: 24 types of logical devices, 5 types of amplifiers, and 5 types of time bases.

The pre-shot sequence of commands is:

OPEN, ARM, TRIG, BASE, ARM.

This sequence takes a base line and prepares the recorders for the shot. Aftcr the machine trigger, the post-shot command sequence is:

READ, SAVE, CLOSE.

This records the data from ali "active" diagnostics in a temporary shot flle and archive:s the data from each diagnostic with a "save" status. These commands may be execuled only by a program having the full rights of rhe experimert. Anyone can use the commands for dala analysis and vlewing.

For an experinent that is not smpute: controlled, these sequences ate requested interactively. To simplify things for the manual 
user, any sequence of commands can be associated with a number and theil be invoked by using only that number. These definitions and the paraneters used by the DAD routines are retained In personal files. For an experiment that is computer controlled, the sequences are invoked from command files.

The experimenters may check a recorder by cycling $i t$ and 1 laplaying any test input or they may see the range of data values to adjusi an Input offset or to check for noise. While the experiment is collecting data, the devices are off-limits.

IV. DATA COMPRESSION

Data compression is normally part of the READ command processing. The data may be unpacked (one 1 tem in each compurer word), packed into a bit stream (using a word size that depends on the device), or compressed. T'he chotce ised is controlled device-ty-device by an eitry li, the logical device descriptor.

The unpacked technique intinimizes CPU timn at the expense of fille size and dist input/output $(I / 0)$ time. The packed technique costs about $50 \%$ 
$-8-$

more CPU :Ime than unpacked but results in a predictable reduction in the file size.

The compression technique records

djfferences between successive data inputs and uses about three times the unpacked CPU time but results in a reduction of the total shot file size by a factor of three to six. Table I shows the number of bytes stored for a typical device.

For compression to be effective, the data must change slowly. Each data trace is differenced to get a starting value and the successive changes. If it changes slowly then those changes will be small and can be stored using fewer bits per data item. The algorithm scans the trace to make divisions into groups that will minimize the total bits needed. As a

Table I. Storage for a typical 10-bit device.

$\begin{array}{cc}\text { saved descriptor } & 188 \text { bytes } \\ \text { optional words } & 4 \\ \text { unpacked data } & 16384 \\ \text { packed data } & 10240 \\ \text { compressed data } & 2400\end{array}$


compromise to reduce the time used, it projects ahead only one group. Each group is preceded by an item count and the number of bits used to represent each item.

The system has the flexibility to defer the data compression until SAVE time or until off-hours. It has been our experience, however, that the elapsed real time to compress the data during the READ processing is not significantly more than that for unpacked or packed data because the disk I/0 time is greatly reduced.

The expansion of compressed data takes more time than using unpacked data but that ertra time is only about $10 \%$ of the simplest retrieval and is often less than that needed for packed data. Data compression also allows more shots to be avallable on disk before transfer to permanent storage and the I/0 time is reduced.

On our largest experiment (ZT-40M), a typical shot has 1.4 million items from 220 devices used by 26 diagnustics. The READ and SAiE takes 200 seconds and 700 compressed shots are stored on disk. 
v. SUMMARY

The separation of device descriptors from the programming allows the use of one set of programs on a variety of experiments. The compression of cata permits reduced storage and expanded avallability of older shots with a small real-time penalty. 
$-11-$

${ }^{1} \mathrm{~K}$. A. KLARE, "Magnetic-Fusion Data Analysis at Los Alamos," submitted to these proceedings. 